\title{
Przyczynek do badań nad początkiem Cerkwi na Zachodzie Rusi*
}

\author{
Radosław Liwoch \\ Muzeum Archeologiczne w Krakowie \\ liwoch@ma.krakow.pl
}

\begin{abstract}
Radosław Liwoch, Contributions to the Study of the Beginnings of the Orthodox Church in Western Rus', Elpis, 16 2014: 169-172.
Abstract: In 1882 T. Ziemięcki conducted in Pidgìrci (Lviv district, Ukraine) a research excavation of two neighboring burial mounds which he called the Great Twin Barrows No. 1 and No. 2. In barrow No., he discovered on richly furnished double burial (probably of a married couple) where he found two identical silver crosses. The crosses belong to the so called Scandinavian type (variant B.1 type 1.4.3 acc. J. Staecker). In barrow No. 2, he found a skeleton of a male buried with furnishings, including two crosses. The bigger one (lost) was a bronze encolpion depicting the Crucifixion and the Virgin Orans, which can find analogies in the Danube countries. The smaller one is a silver St. Peter's cross. In the mouths of the corpses found in both barrows there were tiny gold objects which could be interpreted as a local variation of the obolus of the dead custom. Both graves are a part of necropolis with druzhina burials. They date back to the end of the $10^{\text {th }}$ century or the first half of the $11^{\text {th }}$ century. The objects presented here are the earliest evidence to confirm the presence of a Christianized (Greek version of Christianity) elite in the region of the Upper Bug and Upper Dniester, which is not burdened with chronological or interpretative reservation. The deceased were not members of the clergy but, nevertheless, representatives of the new official religion in a pagan Slavic population whose conversion had barely begun. It seems, therefore, that their presence in Pidgìrci can be considered the beginning of the Orthodox Church in the western part of the former Kievan Rus'.
\end{abstract}

\begin{abstract}
Streszczenie: W 1882 r. T. Ziemięcki przeprowadził w Podhorcach (obwód lwowski, Ukraina) badania wykopaliskowe dwóch sąsiadujących ze sobą kurhanów, które nazwał wielką mogiłą bliźniaczą $\mathrm{nr} 1$ i nr 2 . W mogile $\mathrm{nr} 1$ odkrył bogato wyposażony pochówek podwójny (zapewne małżeński), w którym znajdowały się dwa identyczne srebrne krzyżyki. Krzyże te należą do typu nazywanego skandynawskim (wariant B.1 typu 1.4.3 wg J. Staeckera). W mogile $\mathrm{nr} 2$ znalazł szkielet mężczyzny, którego pochowano $\mathrm{z}$ wyposażeniem, w tym z dwoma krzyżami. Większy (zaginiony) był brązowym enkolpionem z wyobrażeniem Ukrzyżowania i Matki Boskiej Oranty, który znajduje analogie w krajach naddunajskich. Mniejszy jest srebrnym krzyżykiem w formie krzyża św. Piotra. W ustach zmarłych pochowanych w obu kurhanach znajdowały się drobne przedmioty złote, które interpretować należy jako lokalny wariant zwyczaju obola zmarłych. Oba groby są częścią nekropoli z pochówkami drużynnymi. Datować je trzeba na koniec X - 1. połowę XI w. Przedstawiane obiekty są najstarszymi niebudzącymi wątpliwości chronologicznych i interpretacyjnych śladami obecności schrystianizowanych (grecka wersja chrześcijaństwa) elit nad górnymi Bugiem i Dniestrem. Zmarli nie będąc duchownymi, byli jednak przedstawicielami nowej oficjalnej religii wśród słowiańskiej ludności, której nawracanie dopiero się rozpoczynało. Wydaje się zatem, że ich obecność w Podhorcach uznać można za początek Cerkwi w zachodniej części niegdysiejszej Rusi Kijowskiej.
\end{abstract}

Keywords: Kievan Rus', Christianity, princely retinue (druzhina), burial mounds, obolus of the dead, crosses

Słowa kluczowe: Ruś Kijowska, chrześcijaństwo, drużyna książęca, kurhany, obol zmarłych, krzyże

W 1882 r. Teodor Ziemięcki z Krakowa rozpoznał archeologicznie dwa sąsiadujące ze sobą kurhany, które nazwał wielką mogiłą bliźniaczą nr 1 i nr 2 (dalej: WMB1 i WMB2; por. ryc. 1), położone w Podhorcach, w miejscu latopisowego Pleśniska ${ }^{1}$. Uzyskane materiały przedstawił pokrótce (Ziemięcki 1883, 43-48), miał bowiem zamiar niezrealizowany - późniejszego ich opracowania ${ }^{2}$. Obecnie przechowywane są one w Muzeum Archeologicznym w Krakowie (nr inw. MAK/3744). Szczególnie istotne jest, że znajdują się wśród nich zabytki, które łączyć można z początkami Cerkwi ruskiej.

\footnotetext{
W artykule zastosowano transliterację znaków cyrylickich na znaki lacińskie wg polskiej normy PN-ISO 9 z lutego 2000 r. (wersja normy międzynarodowej ISO 9:1995).

Wieś Podhorce, rejon brodowski, obwód lwowski, Ukraina. Więcej informacji o Pleśnisku znajduje się $\mathrm{w}$ opracowaniu średniowiecznych grodzisk zachodnioukraińskich sporządzonym przez autora (Liwoch 2003, 217, 260-261).

2 Materiały z WMB1 i WMB2 autor zaprezentował szerzej w artykule sprzed kilku lat (Liwoch 2009; tam lit.; patrz też: Liwoch 2007, 369-377; 2010; 2012).
}

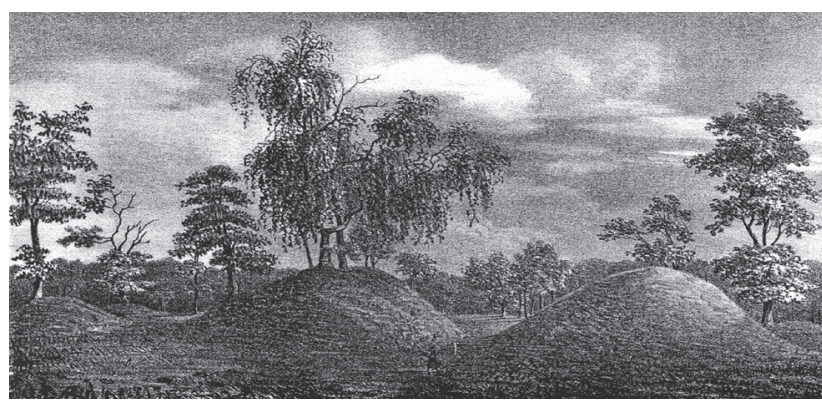

Ryc. 1. Widok (zapewne stylizowany) na cmentarzysko kurhanowe latopisowego Pleśniska (wg Stęczyński 1847 /1990/, ryc. przed s. 125)

Jako pierwsza badana była WMB1. Kurhan ten miał wysokość ok. 2 i średnicę ok. $16 \mathrm{~m}$. Zawierał pozostałości konstrukcji drewnianych (rodzaj komory?). Na głębokości ok. 2,75 m od wierzchołka kopca spoczywały na wznak dwa szkielety z czaszkami po stronie zachodniej (ryc. 2). Inwentarz grobowy był bogaty i różnorodny (fot. 1). Z mężczyzną wiążą się: żelazny nadreński miecz typu V wg J. Petersena, brązowy bałtyjski trzewik pochwy typu IIIc wg V. Kazakevičiusa, dwa srebrne węgierskie okucia pasa, żelazny czekan 


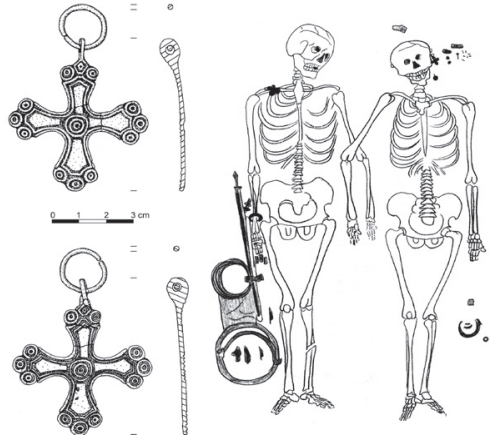

Ryc. 2. WMB1, pochówek i krzyże (Archiwum MAK i rys. A. Dziedzic)

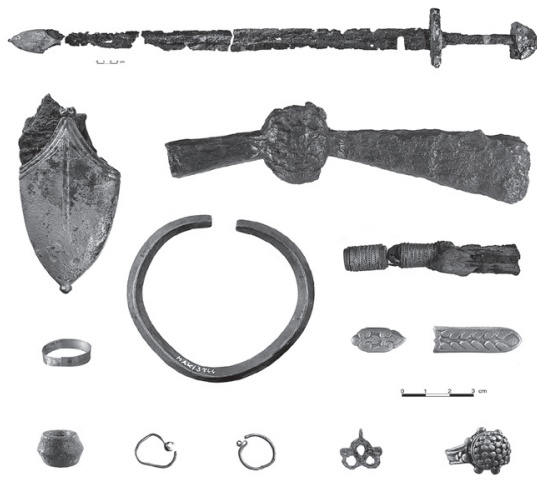

Fot. 1. Wybór wyposażenia z WMB1 (fot. A. Susuł)

typu I wg A.N. Kirpičnikova, srebrna - może skandynawska - bransoleta, złoty i dwa srebrne pierścienie oraz inne przedmioty; z kobietą zaś m.in.: trzy srebrne pierścienie (jeden $\mathrm{z}$ tarczką malinowatą), srebrne esowate kabłączki skroniowe, a także bizantyjskie oraz bliskowschodnie paciorki z kamieni półszlachetnych i szkła. Uwagę zwracają dwie złote blaszki znalezione w ustach zmarłych oraz dwa srebrne krzyżyki (fot. 2, ryc. 2). Te ostatnie należą do typu

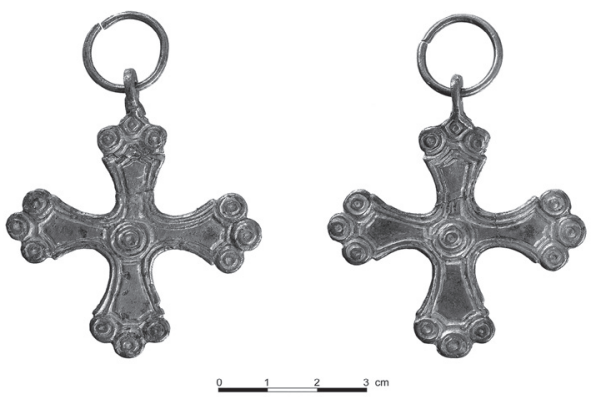

Fot. 2. Krzyżyki z WMB1 (fot. A. Susuł)

tzw. skandynawskiego, ale lepiej oznaczać je jako wariant B.1 typu 1.4.3 wg J. Staeckera. Odlane zostały w tej samej formie najpewniej na Rusi, gdzie pod wpływem bizantyjskim wytwarzano takie dewocjonalia. Przyjąć można, że były one pamiątką baptyzmalną - prawdopodobnie jednoczesnego przyjęcia chrztu przez małżonków - choć mają również walor estetyczny. Datować je trzeba na schyłek X lub pierwsze dziesięciolecia XI w. Podobna jest chronologia WMB1 (Liwoch 2009, 363-365).

WMB2 badano jako drugą. Był to kurhan o średnicy ok. $16 \mathrm{~m}, \mathrm{z}$ widocznymi śladami wcześniejszego rozkopywania. Na głębokości $2 \mathrm{~m}$ od jego wierzchołka, bezpośred-

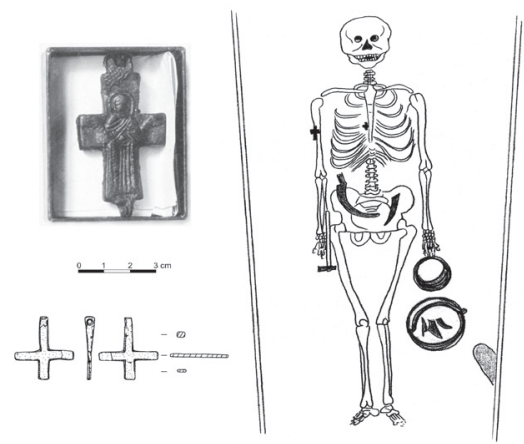

Ryc. 3. WMB2, pochówek i krzyże (Archiwum MAK i rys. A. Dziedzic)

nio pod nasypem z warstwą węgla (pozostałości konstrukcji drewnianej?) znajdował się szkielet głową skierowany ku południowemu zachodowi (ryc. 3). Na wyposażenie (fot. 3)

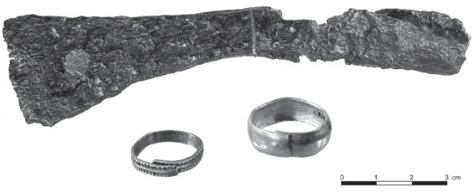

Fot. 3. Wybór wyposażenia z WMB2 (fot. A. Susuł)

zmarłego składały się: żelazny czekan typu I wg A.N. Kirpičnikova, żelazny sierp, dwa złote pierścienie i inne rzeczy. Również w tym grobie znajdowały się ciekawe dewocjonalia - brązowy enkolpion i srebrny krzyżyk, a w ustach zmarłego złoty drucik (fot. 4). Relikwiarzyk jest zapewne

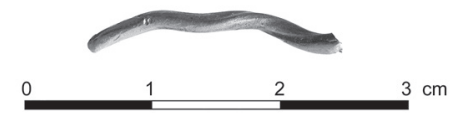

Fot. 4. Obol zmarłego z WMB2 (fot. A. Susuł)

wyrobem bułgarskim $\mathrm{w}$ typie bizantyjskim, $\mathrm{z}$ reliefowymi wyobrażeniami Ukrzyżowania i Matki Boskiej Orans (ryc. 3; por. fot. 5). Nie ma on bliskich analogii na Rusi Kijow-

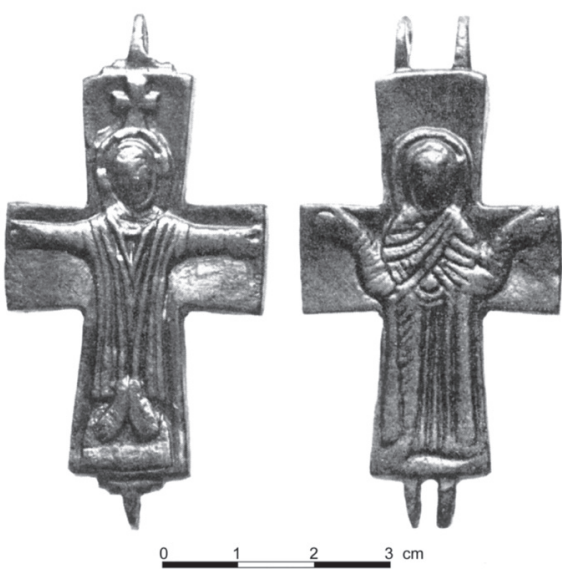

Fot. 5. Enkolpion z Vésztő na Węgrzech (wg Lovag 1971, 145 /ryc. 1:2a, 2b/) - analogia do zaginionego okazu z Podhorzec Pleśniska

skiej, z której znane są importowane egzemplarze reliefowe, lecz zwykle o bogatszej ikonografii (por:: Korzuhina, Peskova 2003; Peskova 2012). Podobne do niego znajdowane są na obszarze od Węgier po Grecję. Enkolpion podhorecki datować można na koniec X lub XI w. (por.: Pitarakis 2006, 231-233; Liwoch 2009, 368-369; tam lit.). Zawieszka ze sre- 
bra ma kształt krzyża św. Piotra. Jest surowa w formie i ulana niezbyt starannie (ryc. 3, fot. 6). Znakomicie potwierdza

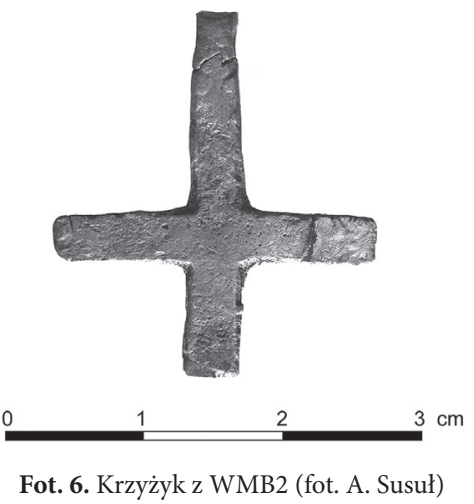

obserwację A.-S. Gräslund, że krzyżyki wykonywano niedbale i na niskim poziomie technicznym, co byłoby niezrozumiałe, gdyby miały służyć tylko do ozdoby (por. Staecker 1999, 20). Zatem przypuszczać można, iż okaz podhorecki jest pamiątką chrztu właściciela. Zalicza się do datowanego na X - 1. połowę XI w. wariantu A typu 1.1.2 wg J. Staeckera. Cały zespół grobowy WMB2 pochodzi z 1. połowy XI w. lub ewentualnie $\mathrm{z}$ samego końca stulecia poprzedniego (Liwoch 2009, 368-369).

W ustach zmarłych z WMB znajdowały się drobne przedmioty złote, które interpretować należy jako tzw. obole zmarłych. Niejasne jest ich realne znaczenie, żadna bowiem z możliwości - dostarczenie zmarłym opłaty za przewóz w zaświaty (obol Charona) lub gotówki na pośmiertne zakupy (eliminacja darów grobowych), bądź też zabezpieczenie się (przez przekupienie) przed powrotem nieboszczyka do świata żywych - nie wydaje się w pełni wiarygodna. Zwyczaj wyposażania zmarłych w monetę( -y) jest lub był kultywowany w różnych częściach świata, jednak trudno znaleźć analogię do zabytków podhoreckich (Liwoch 2009, 370; tam lit.). A.P. Mocâ (1990, 106) doszukuje się w omawianych pochówkach wpływu tradycji wielkomorawskiej, ponieważ właśnie tam odnotowano w grobach złote obole zmarłych - blaszki i bizantyjski solid cesarza Michała III (Poulík 1975, 86, tabl. 6, 51). Bardziej uzasadnione jest interpretowanie drobnych złotych przedmiotów z ust pochowanych w Podhorcach oraz znalezisk z Wielkich Moraw jako lokalnych, niepowiązanych ze sobą przykładów omawianego zwyczaju. Wkładane zwykle do grobów srebrne monety lub ułamki monet zastąpiono złotymi blaszkami i drucikiem, które uznać trzeba za namiastki bizantyjskiego pieniądza złotego będącego w obiegu na południe od Karpat, a także na południowej Rusi. Zauważyć można, że zwyczaj obola zmarłych wystąpił zarówno u Słowian, jak i u Węgrów oraz Skandynawów w okresie ich chrystianizacji ok. przełomu I na II tysiąclecie n.e., chociaż nie był związany z wymogami nowej religii.

Ważniejsze od fenomenu podhoreckich oboli zmarłych są dewocjonalia - niewątpliwie demonstracja wiary w Jezusa Chrystusa - złożone ze zmarłymi do WMB1 i WMB2. Ich posiadacze należeli prawdopodobnie do elit Rusi Kijowskiej i byli związani z księciem Włodzimierzem Wielkim (ok. 958-980-1015 r.). Rezydowali w strategicznie korzystnym miejscu u źródeł Bugu, Styru i Seretu (dorzecza Wisły, Prypeci i Dniestru) sprawując kontrolę nad obszarem niedawno (981 r.?) wcielonym do monarchii kijowskiej. Przypuszczalnie działo się to już po przyjęciu chrztu przez Włodzimierza (988 r.). Wychodząc z założenia, że bóg władcy powinien być bogiem całej wspólnoty, książę ten musiał pozbawić swych poddanych możliwości wyboru wyznania - ważnego elementu życia społecznego. Chrystianizator mógł spodziewać się oporu części społeczeństwa, jednak monoteistyczne chrześcijaństwo w wersji bizantyjskiej, które wprowadził, nadawało się znakomicie na sprzymierzeńca budowniczego państwa ${ }^{3}$. Jako pierwsza nową religię zaakceptować musiała - a zapewne chciała książęca drużyna. To rzeczywiście nastąpiło - przykładem zmarli z WMB - choć zmiany światopoglądowe i przyswajanie eschatologii chrześcijańskiej zachodziły powoli. Ważne, że chrześcijanina tworzył nieodwracalnie sam obrzęd chrztu, którego pamiątkami są - jak już wspomniano - krzyże z obu grobów. Są one też najstarszym niebudzącym zasadniczych wątpliwości chronologiczno-interpretacyjnych świadectwem obecności chrześcijan na zachodzie współczesnej Ukrainy i terenach sąsiednich. Właściciele krzyżyków przybyli najpewniej znad Dniepru jako przedstawiciele władzy kijowskiego księcia, dzięki której działalność misyjną rozwijał Kościół wschodni ${ }^{4}$. Związek pochowanych w WMB z kultem państwowym nie wyklucza ich indywidualnego zaangażowania, które widoczne jest - choć może to tylko ostentacja - zwłaszcza w WMB2. Zmarli nie będąc duchownymi, byli jednak nosicielami nowej oficjalnej religii wśród słowiańskiej ludności, której nawracanie dopiero się rozpoczynało. Wydaje się zatem, że ich obecność w Pleśnisku uznać można za początek Cerkwi ${ }^{5}$ w zachodniej części niegdysiejszej Rusi Kijowskiej.

\footnotetext{
3 Roli takiej nie mogła odegrać religia pogańska, czego dowodem była nieudana próba wprowadzenia w Kijowie henoteizmu.

4 Chrystianizacja państwa ruskiego bez wątpienia była jego najważniejszym osiągnięciem.

5 Organizacja Cerkwi na zachodzie Rusi w wysokim stopniu zależała od sytuacji politycznej i nie ma tu miejsca na jej szczegółowe omawianie. Nadmienić jednak można, że diecezję w Haliczu erygowano ok. połowy XII w., a jej biskupi wzmiankowani są pod ok. 1153 r. - Aleksy (niepewny); 1156 (ingres) i 1165 r. - Kosma oraz pod 1235 i 1241 r. Artemiusz. Wspominani są też biskupi przemyscy - Antoni, którego z arcybiskupstwa nowogrodzkiego przeniesiono w 1220 r., powrócił zaś do Nowogrodu w 1225/1226 r. oraz nieznanego imienia władyka przemyski pod r. 1241 (Osadczy 2001, 297-300). Wcześniejszą metrykę ma stolica biskupia we Włodzimierzu Wołyńskim, lecz jej fundatorem nie był raczej Włodzimierz Wielki (niewiarygodna jest wzmianka w późnym „Latopisie Nikona" o biskupie Szczepanie/Stefanie), a powstała ok. 1078-1088 lub ok. 1090 r. (Vlasto 2004, 311, 448). Działali, oczywiście, duchowni niższej rangi, jak ok. XI/XII w. przemyski pop Wasyl będący powiernikiem i przypuszczalnie spowiednikiem księcia Wasylka Rościsławicza (Powieść... 1999, L-LI, 202).
} 


\section{Bibliografia}

Korzuhina G.F., Peskova A.A.

2003 Drevnerusskie ènkolpiony. Nagrudnye kresty-relikvarii XI -XIII vv., Sankt-Peterburg.

Liwoch R.

2003 Stan badań nad grodziskami wczesnośredniowiecznymi i z początków późnego średniowiecza na zachodniej Ukrainie (obwody: iwano-frankowski, lwowski i tarnopolski), Materiały i Sprawozdania Rzeszowskiego Ośrodka Archeologicznego 24, s. 213-297.

2007 Wielkie kurhany latopisowego Pleśniska, Materìali ì doslìdžennâ z arheologiï Prikarpattâ ì Volinì 11, s. 367-378, fot. 28-31.

2009 Wielka mogiła bliźniacza $w$ Podhorcach, [w:] Spotkania Bytomskie 6, Stare i nowe w średniowieczu. Pomiędzy innowacja a tradycja, red. S. Moździoch, Wrocław, s. 357-377.

2010 Bol'šie kurgany letopisnogo Plesneska, [w:] Slavâno-russkoe ûvelirnoe delo i ego istoki, red. A.A. Peskova i in., Sankt-Peterburg, s. 486-492, tabl. 12.

2012 On the new border of Christian civilisations. Archeological material from the early Rus' Plisnesk, [w:] Rome, Constantinople..., s. 611-619.

Lovag Zs.S.

1971 Byzantine Type Reliquary Pectoral Crosses in the Hungarian National Museum, Folia Archaeologica 22, s. 143-164.

Mocâ A.P.

1990 Pogrebal'nye pamâtniki ĥžnorusskih zemel' IX-XIII vv., Kiev.

Osadczy O.

2001 Powstawanie pierwszych biskupstw na Rusi Halickiej, [w:] Dzieje Podkarpacia 5, Początki chrześcijaństwa w Małopolsce, red. J. Gancarski, Krosno, s. 293-300.
Peskova A.

2012 Byzantine pendant reliquary-crosses from the territory of medieval Rus', [w:] Rome, Constantinople..., s. 403-443.

Pitarakis B.

2006 Les croix-reliquaires pectorales byzantines en bronze, Bibliothèque des Cahiers archéologiques 16, Paris.

Poulík J.

1975 Sídlo a pevnost knižat velkomoravských, Praha.

Powieść...

1999 Powieść minionych lat, przełożył i opracował F. Sielicki, Wrocław.

Rome, Constantinople...

2012 Rome, Constantinople and newly-converted Europe. Archaeological and historical Evidence 2, red. M. Salamon i in., U źródeł Europy Środkowo-Wschodniej / Frühzeit Ostmitteleuropas 1, Kraków - Leipzig - Rzeszów - Warszawa.

Staecker J.

1999 Rex regum et dominus dominorum. Die wikingerzeitlichen Kreuz- und Kruzifixanhänger als Ausdruck der Mission in Altdänemark und Schweden, Lund Studies in Medieval Archaeo$\operatorname{logy} 23$, Stockholm.

Stęczyński M.B.

1847 (1990) Okolice Galicyi, Lwów (reprint w Krakowie + dodatek).

Vlasto A.P.

2004 Zaprovadžennâ hristiânstva u slov'ân. Vstup do seredn'ovičnoï istorï slov'ânstva, Kiïv.

Ziemięcki T.

1883 Sprawozdanie $z$ wycieczki archeologicznéj do Podhorzec w roku 1882 dokonanéj przez T. Ziemięckiego, Zbiór Wiadomości do Antropologii Krajowéj 7, s. 41-50.

Rozmiar artykułu: 1 arkusz wydawniczy 